\title{
COMMUNITY ECOLOGY IN BEES: RELATIVE IMPORTANCE OF RARE AND COMMON SPECIES IN SOME HOLARCTIC AND NEOTROPICAL SITES ${ }^{1}$
}

\author{
Sebastião Laroca ${ }^{2}$
}

\begin{abstract}
Data on relative importance of rare and common bee species in some holarctic and neotropical limited sites are presented. The density distribution patterns in samples from all analyzed assemblages is characterized by a relatively large number of species represented by few individuals and few species with large number of individuals, as in most animal communities.

KEY WORDS. Ecology, community, neotropical-bees, holarctic-bees
\end{abstract}

Insect samples from sites of various geographical regions, sampled by different methods, e.g. Haw-moths caught in light traps (see WILLIAMS (1964), LAROCA \& MIELKE (1975), LAROCA et al. (1989), Lepidoptera caught in suction traps, Tipulidae caught in a light trap, Coleoptera caught in sea-shore drift and river flood refuse, Carabidae caught in ground traps, Diptera (Limosina, Borboridae) caught in cow-dung, soil Collembola caught in dead leaves, in moss on stones and in an alpine situation (see WILLIAMS, 1964) follow the same general pattern. Such distribution is characterized by a large number of species represented by few inividuals and few species with large numbers of individuals. This work is one of the outcomes of periodical samplings of flower-visiting wild bees made in certain holarctic and neotropical limited sites. The numbers of species and individuals were extracted from such samples in order to analyze the relative importance of rare and common species.

\section{MATERIAL AND METHODS}

The main procedure for sampling was basically that utilized by SAKAGAMI et al. (1967), which consists of collecting wild bees on flowers or in flight near the flowers without selecting which bees are to be taken. Some details are also given by SAKAGAMI \& LAROCA (1971a and b). The samples were separeted on an hourly basis. Each bee was collected individually or in a group, but not by random sweeping. The specimens were put separately into killing tubes according to the flowers visited (the number of killing tubes corresponded to the number of kinds of plants in bloom in the field that). Data

1) Contribuição número 766 do Departamento de Zoologia, Universidade Federal do Paraná.

2) Departamento de Zoologia, Universidade Federal do Paraná, Caixa Postal 19020, 81531-970 Curitiba, Paraná, Brasil. 
on the number of nests per species of bees recorded in a earth bank are also studied. The accumulated percentages of species (horizontal ordinate) are plotted against the accumulated percentages of individuals or nests (vertical ordinate). The sources of the informations as well as the abbreviation for each site are given at each figure.

\section{RESULTS}

All curves (Figs 1 to 13) present the same general form, starting with a rapid increase in species number and an almost imperceptible rise in the percentage of individuals (or nest, for Fig. 13). The percentage of individuals changes rather suddenly, usually in the neighborhood of 80 to 90 percent of the species, to a rapid rise in the number of individuals associated with a few remaining species.

In WC (Fig. 1) (total: 4,116 individuals belonging to 141 species), $50 \%$ of the rarer species account for only about $2.8 \%$ of the total individuals, while the single most abundant species accounts for $19.2 \%$ of the individuals. Half of all the individuals belong to the six most abundant species $(4.3 \%$ of the total species represented).

In RFP (Fig. 2) (total: 1,284 individuals belonging to 90 species), the insignificance of rare species and the predominance of the more abundant ones are less extreme. Half of the rarer species accounts for about $4.7 \%$ of the total individuals, while the single most abundant species accounts for about $15.4 \%$. Half of all individuals belongs to the six most abundant species, wich is $6.7 \%$ of the total number of species.

In RFT (Fig. 3) (total: 230 individuals belonging to 31 species), $50 \%$ of the rarer species account for $8.5 \%$ of the total individuals, while the single most abundant species accounts for $43.5 \%$. About half of all the individuals belongs to only two of the most abundant species, which is $6.5 \%$ of the species. Relative proportions of rare to common species in this site differ from WC and RFP, in the allocation of individuals of the rarer species as well as in an uneven representation of the single most abundant species. These differences may be a consequence of site disturbance or of small sample size.

In UC (Fig. 4) (total: 3,106 individuals belonging to 77 species), 50\% of the rarer species account for about $4.8 \%$ of the total individuals, while the single most abundant species accounts for $15 \%$. Almost half of all individuals belongs to seven species, which is $8.2 \%$ of the total species.

In BG (Fig. 5) (total: 3,744 individuals belonging to 85 species), $50 \%$ of the rarer species account for $3.5 \%$ of the total individuals, while the single most abundant species accounts for $11.1 \%$. Almost half of all the individuals belongs to seven species, which is only $7.5 \%$ of the total species.

In OU (Fig. 6) (total: 2,230 individuals belonging to 88 species), $50 \%$ of rarer species account for $4.8 \%$ of the total individuals, while the single most abundant species accounts for $16.4 \%$. Half of all individuals belongs to five species, which is only $5.1 \%$ of the total species. 
Data from SJP, BV and ALX are plotted as a whole (Figs 7-9) and with the Apidae excluded (Figs 10-12). The latter representation was done to avoid the influence of the highly social meliponines which in some instances are represented by numerous specimens.
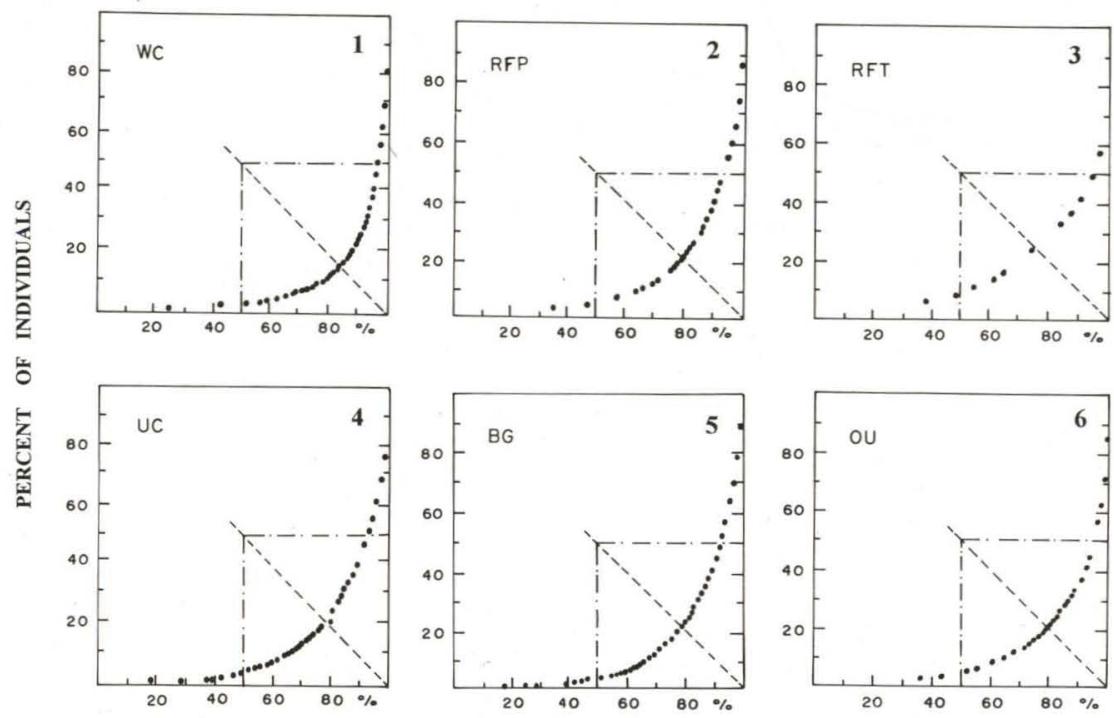

PERCENT OF SPECIES

Figs 1-6. Relative abundance (\%) of rare and common species of bees at various holarctic sites. The accumulated number of individuals (\%) (vertical ordinate) is plotted against the accumulated number of species (\%) (horizontal ordinate). Lawrence, KS, U.S.: (1) West Campus, KU (WC); (2) River Front Park (RFP); (3) Rockefeller Tract (RFT). Sapporo, Hokkaido, Japan: (4) University of Hokkaido Campus (UC) (Source of data: SAKAGAMI \& FUKUDA, 1973); (5) The University of Hokkaido Botanical Garden (BG) (Source of data: SAKAGAMI \& FUKUDA, 1973). Obihiro, Hokkaido, Japan: (6) Obihiro (OU) (Source of data: USSUI et al. (1976).

In SJP (Fig. 7, 10) (total: 4,215 individuals belonging to 167 species, Apidae excl: 3,137 individuals belonging to 162 species), $50 \%$ of the rarer species account for $3.1 \%$ (4.1\%, excluding Apidae) of the total individuals, while the single most abundant species accounts for $16 \%(18.6 \%)$. Half of all the individuals belongs to six species (or nine), which is $3.6 \%$ (or $5.6 \%$ when Apidae are excluded) of all species.

In BV (Figs 8,11)(total: 1,919 individuals belonging to 159 species, Apidae excl.: 1,605 belonging to 149 species), rarer species are slightly less insignificant, $50 \%$ of the rarer species account for $6 \%$ (or $6.6 \%$ ) of the total individuals, while the single most abundant species accounts for $10.1 \%$ (or $12.1 \%$ ). Half of all the individuals belongs to 11 species (or nine species), which 

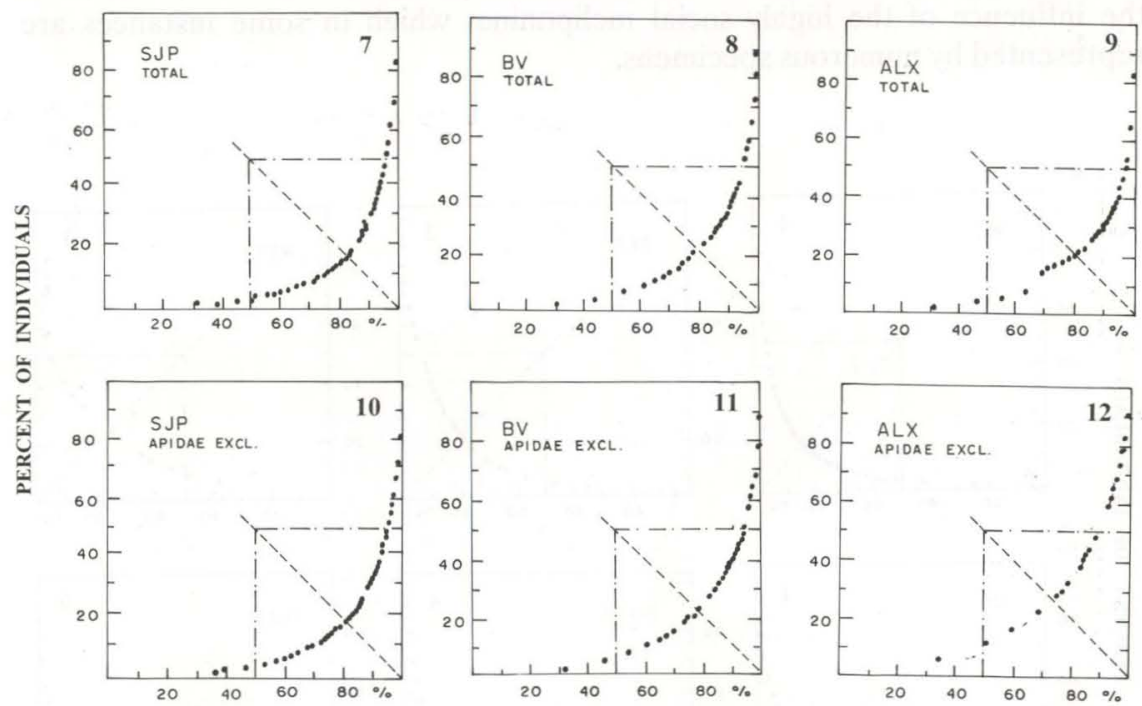

PERCENT OF SPECIES

Figs 7-12. Relative abundance (\%) of rare and common species of bees at various neotropical sites. The accumulated number of individuals (\%) (vertical ordinates) is plotted against the accumulated number of species (\%) (horizontal ordinate). São José dos Pinhais (SJP, TOTAL) (Source of data: SAKAGAMI, LAROCA \& MOURE, 1967). Curitiba, PR, Brasil: (8) Boa Vista (BV, TOTAL) (Source of data: LAROCA, 1974). Paranaguá, PR, Brasil: (9) Alexandra (ALX, TOTAL) (Source of data: LAROCA, 1974). (10) as in figure 7, but excluding Apidae (SJP, APIDAE EXCL.); (11) as in figure 8, but excluding Apidae (BV, APIDAE EXCL.); (12) as in figure 9, but excluding (ALX, APIDAE EXCL.).

is $6.9 \%$ (or $6 \%$, excluding Apidae) of all species.

In ALX (Figs 9, 12)(total: 1,881 individuals belonging to 120 species), $50 \%$ of the rarer species account for $4.5 \%$ (or $11.3 \%$ ) of the total individuals, while the single most abundant species accounts for $18.8 \%$ (or $10.5 \%$ ). Half of all the individuals belongs to four species (or 12 species), which is $3.3 \%$ (or $11.9 \%$ excluding Apidae) of the total number of species.

In BA (Fig. 13)(total: 3,964 nests belonging to 27 species), $50 \%$ ot the rarer species account for $1.2 \%$ of the total nests in the roadside banks, while the single most abundant species accounts for $71 \%$. This species is $3.7 \%$ of the total number of species.

\section{COMMENTS}

There are three models by which relative abundance of animals in communities can be described. These models are as follows: 1 , random niche 


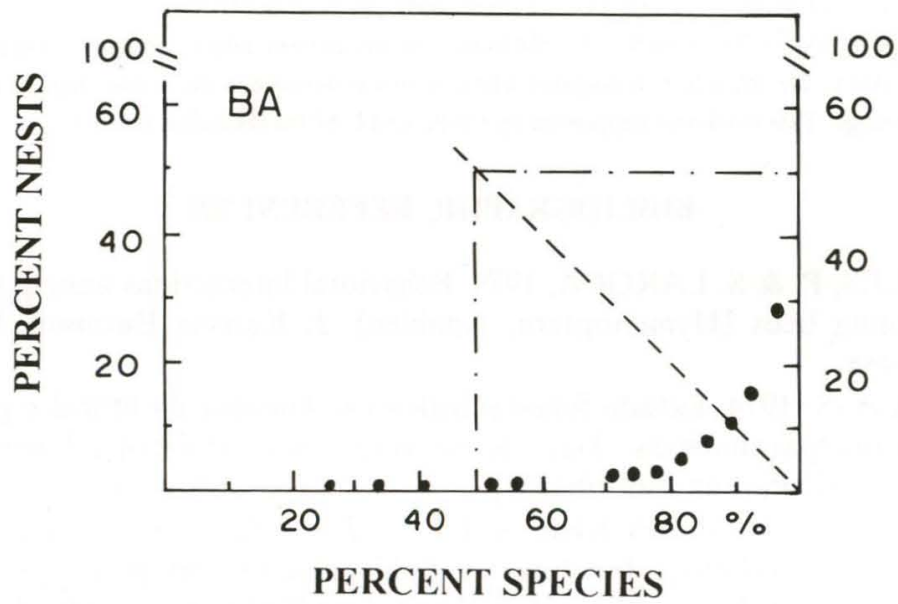

Fig. 13. Relative abundance (\%) of rare and common species of bees in a neotropical site: Barigui, Curitiba, Brazil (Source of data: Michener et al., 1958).

bondaries, or broken stick model (MACARTHUR, 1957), 2, the niche preemption model (MOTOMURA, 1932) and 3, lognormal model (PRESTON, 1948). Data from SJP, BG and UC fit a lognormal distribution (cf. SAKAGAMI \& FUKUDA, 1973). Data from other places also at least roughly fit a lognormal distribution. This distribution predicts a few abundant species, many species of moderate abundance and few rare species. Therefore, in the present case it has to be postulated that most of rare species in the sample would acquire a higher relative importance rank if the capture effort were increased, due to the discovery of still rarer species. This seems to be the case. In WC (about two years of capture effort) $24.8 \%$ of the total species are represented by just one individual, while in RFP (about one year of effort) $35.6 \%$ of the species are so represented and in RFT (just one season) the figure is 38.7\%. As WHITTAKER (1972) points out, Preston's truncated lognormal model, as well as the other two, "have not been as useful as we would have liked since the interpretation of the preocesses that result in these distributions is a tactic of weak inference". Thus, in order to extract stronger ecological inferences, it seems necessary to superimpose on relative abundance curves the distributions based on the relative importance of each species measured by means of intra- and interspecific interactions. Resources should be concentrated in space and in time. Floral resources have naturally such properties, being therefore appropriate for this purpose. Empirical experiences indicate that small and isolated flower patches with few clustered flowers provide good conditions (see LAROCA \& WINSTON (1978), DECELLES \& LAROCA (1979), LAROCA \& 
DEQUECH (1979) for such observations.

ACKNOWLEDGEMENTS. I dedicate this paper to Padre Jesus Santiago Moure for his eighty years of existence, most of which expent in the study of neotropical bees. I wish to express my sincere thanks to Dr. Charles D. Michener for his patient advise and encouragement. My gratitude also to Dr. Shoichi F. Sakagami, whose help was decisive in the inicial stage of my studies on bee ecology. This work was supported by CNPq and CAPES (Brasilia, Brazil).

\section{BIBLIOGRAPHIC REFERENCES}

DECELES, P. \& S. LAROCA. 1979. Behavioral interactions among solitarily foraging bees (Hymenoptera, Apoidea). J. Kansas Entomol. Soc. 52: 483-488.

LAROCA, S. 1974. Estudo feno-ecológico em Apoidea do litoral e primeiro planalto paranaenses. Tese de mestrado, não publicada, Universidade Federal do Paraná, Curitiba, 61p.

LAROCA, S.; V.O. BECKER \& F.C.V. ZANELLA. 1989. Diversidade, abundância relativa e fenologia em Sphingidae (Lepidoptera) na Serra do Mar (Quatro Barras, PR), sul do Brasil. Acta Biol.Par., Curitiba, 18: 13-53.

LAROCA, S. \& S.T. DEQUECH. 1979. Interações comportamentais entre abelhas (Hymenoptera, Apoidea) sobre flores de Vernonia westiniana (Compositae). Dusenia 11: 79-81.

LAROCA, S. \& O.H.H. MIELKE. 1975. Ensaio sobre ecologia de comunidade em Sphingidae na Serra do Mar, Paraná, Brasil (Lepidoptera). Revta brasil. Biol. 35: 1-19.

LAROCA, S. \& M.L. WINSTON. 1978. Interaction between Apis and Bombus (Hymenoptera, Apidae) on the flowers of tall thistle; honeybees gather pollen from bodies of bumblebees. J. Kansas Entomol. Soc. 5: 274-275.

MACARTHUR, R.H. 1957. On the relative abundance of bird species. Proc. Nat. Acad. Sci. U.S.A. 43: 293-295.

MOTOMURA, I. 1932. A statistical treatment of associations (in Japanese) Japan. J. Zool. 44: 379-383.

PRESTON, F.W. 1948. The commoness and rarity of species. Part I and II. Ecology 43: 182-215.

SAKAGAMI, SH.F. \& H. FUKUDA. 1973. Wild bee survey at the Campus of Hokkaido University. J. Fac. Sci., Hokkaido Uni., Series VI, Zool. 19: 190-250.

SAKAGAMI, SH.F. \& S. LAROCA. 1971a. Observations on the bionomics of some neotropical xylocopine bees, with comparative and biofaunistic notes (Hymenoptera, Anthophoridae). J. Fac. Sci., Hokkaido Univ., Series VI, Zool. 18: 57-127.

. 1971b. Relative abundance, phenology and flower visits of apid bees in eastern Paraná, southern Brazil (Hymenoptera, Apidae). Konty 39: 217-230. 
SAKAGAMI, SH.F., S. LAROCA \& J.S. MOURE. 1967. Wild bee biocoenotics in São José dos Pinhais (PR), south Brazil. Preliminaty report. J. Fac. Sci., Hokkaido Univ., Series VI, Zool. 16: 253-291.

WHITTAKER, R.H. 1972. Evolution and the measurement of species diversity. Taxon 21: 213-251.

WILLIAMS, C.B. 1964. Patterns in the balance of nature and related problems in quantitative ecology. Academic Press, VII + 324p.

Recebido em 02.XI.1992; aceito em 07.VI.1993. 